\title{
Investigation of the Mechanism of Precipitation of the Ti3Al in Two-Phase Titanium-Aluminium Alloy
}

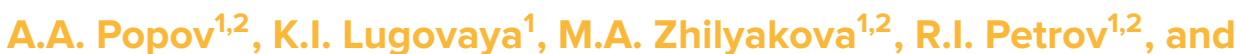 \\ E.N.Popova ${ }^{1,2}$ \\ ${ }^{1}$ Ural Federal University, 19 Mira Street, 620002, Ekaterinburg, Russia \\ ${ }^{2}$ M.N. Miheev Institute of Metal Physics of Ural Branch of Russian Academy of Sciences, $18 \mathrm{~S}$. \\ Kovalevskaya Street, Yekaterinburg, Russia, 620137
}

\section{Abstract}

Changes in the formation processes of the ordered $\mathrm{Ti}_{3} \mathrm{Al}$ phase $\left(\alpha_{2}\right.$ phase) was studied depending on the heat treatment in the $\mathrm{Ti}-\mathrm{Al}$ alloy. It was shown that hightemperature treatment in a single-phase $\alpha$-region, followed by supercooling at different temperatures, leads to a more active release and growth of dispersed particles than after preliminary processing from the $\beta$-region.

Corresponding Author:

A.A. Popov

Received: 25 February 2019

Accepted: 9 April 2019

Published: 15 April 2019

Publishing services provided by Knowledge E

(c) A.A. Popov et al. This article is distributed under the terms of the Creative Commons.

Attribution License, which permits unrestricted use and redistribution provided that the original author and source are credited.

Selection and Peer-review under the responsibility of The Ural school-seminar of metal scientists-young researchers Conference Committee.

\section{Introduction}

Modern high-temperature industrial titanium alloys usually contain aluminum in an amount limited to $8 . . .9 \mathrm{wt} \%$. This limitation is due to the formation of the $\mathrm{Ti}_{3} \mathrm{Al}$ phase $\left(\alpha_{2}\right.$-phase) precipitated in alloys containing more than $6 \% \mathrm{Al}$. It is also known that the concentration of $\beta$-stabilizers can influence the formation of this phase. With their high content, the formation of $\alpha_{2}$-phase is possible with short exposure times during heat treatment, while at low concentrations a longer holding time is required. It is known that the $\mathrm{Ti}_{3} \mathrm{Al}$ phase precipitated in the alloy is ordered (structural type DO19). It can improve the characteristics of heat resistance while plastic properties are reduced due to blocking of dislocations by these particles [1, 2]. However, the effect on mechanical properties may depending on the transformation mechanism. Visco-plastic characteristics of the alloy are at a low level when dispersed particles of an ordered $\alpha_{2}$-phase are formed, which is realized as a heterogeneous transformation by the mechanism of nucleation and growth. While the formation of a two-phase structure by a homogeneous mechanism with the formation of antiphase boundaries (APB) does not lead to a significant decrease in characteristics [3]. 
According to the data of [4], an alloy containing 25.2 at\% Al should be disordered in the quenched state, and according to the results of differential thermal analysis, only after heating above $617^{\circ} \mathrm{C}$ does the ordering $\alpha \rightarrow \alpha_{2}$ occur. The influence of the chemical composition of the alloy and heat treatment on the ordering processes in alloys of the $\mathrm{Ti}$ Al system was studied in [5]. It was established that dispersed ordered particles of the $\alpha_{2}$-phase were formed in alloys that contain from 12 to 21 at.\% Al. Whereas antiphase boundaries were observed after aging in alloys from 21 to 25 at.\% Al.

\section{Material and Methods}

The study was conducted on samples of model cast alloys Ti-17 at.\% Al and Ti-26 at.\% Al. Ingots weighing $3 \mathrm{~kg}$ were subjected to homogenization annealing in a vacuum furnace at a temperature of $1200^{\circ} \mathrm{C}$ for 1 hour, followed by cooling in an oven. Heat treatment of samples consisted in heating to $950^{\circ} \mathrm{C}$ during 1 hour. Quenching into water after high-temperature treatment was carried out for part of the samples, followed by aging at temperatures of 500 and $650^{\circ} \mathrm{C}$ with exposures up to $300 \mathrm{~h}$.

The main research methods were transmission and scanning electron microscopy, performed on Jeol 200CX microscopes with an accelerating voltage of $160 \mathrm{kV}$, as well as JEM-2100C and JSM6490, equipped with energy dispersive composition analyzers. X-ray diffraction analysis was performed on a Bruker D8 Advance diffractometer in $\mathrm{Cu}$ K $\alpha$ radiation.

\section{Experimental Procedure}

According to previous studies [6], fragments of antiphase boundaries are observed in the structure during cooling of the Ti26Al alloy with $1200 \mathrm{C}$, and $\alpha_{2}$-phase reflections are present on the electron diffraction patterns. $\alpha_{2}$-phase reflexes are observed on electron diffraction patterns after quenching an alloy with a lower aluminum content of Ti17Al from both a temperature of $1200 \mathrm{C}$ from a single-phase $\beta$-region and from a temperature of $950 \mathrm{C}$ from a single-phase $\alpha$-region.

The results [7] showed that quenching from single-phase $\beta$-region before aging samples of the Ti17Al alloy leads to the formation of dispersed particles of the $\alpha_{2}$ phase of about 5-10 nm. These particles are formed by the mechanism of nucleation and growth. Antiphase boundaries of the thermal type (homogeneous mechanism) were observed only after carrying out heat treatment on samples of a Ti26Al alloy containing 26 at. \% Al. Isothermal holding after high-temperature treatment at $950^{\circ} \mathrm{C}$ in the single-phase 
$\alpha$-region led to similar results for an alloy containing 17 at. \% Al [7]. At the same time, the homogeneous mechanism ordering was observed in separate volumes after lowtemperature treatment of experimental titanium alloys of the Ti-Al-Sn-Zr-Mo-Si system, containing up to 12.5 at. \% Al, according to the data of [8]. Particles with sizes from 25 to $200 \mathrm{~nm}$ were obtained in the article [9] during long-term aging of an alloy containing 15 at. \%, at temperatures of $450-750{ }^{\circ} \mathrm{C}$ with a delay of up to 500 hours. Aging time of the quenched samples at a temperature of $500{ }^{\circ} \mathrm{C}$ was increased to 100 and 150 hours for further study. As a result of evaluating the results of X-ray phase analysis, it was found that after these heat treatments a two-phase structure $\left(\alpha+\alpha_{2}\right)$ is formed (Fig. 1).

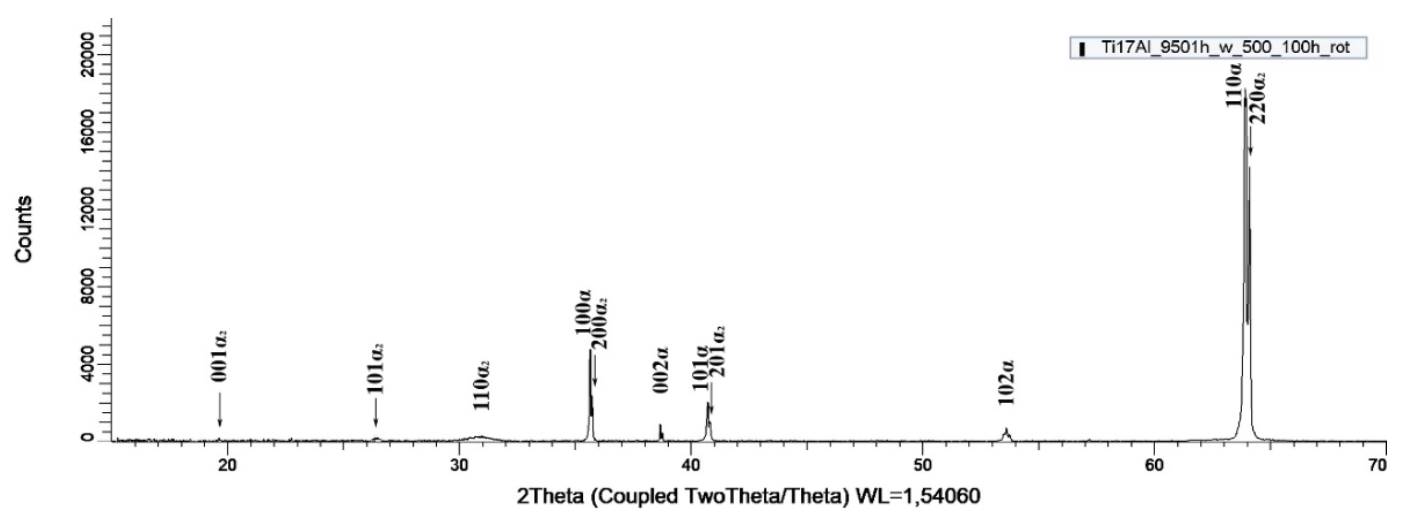

a

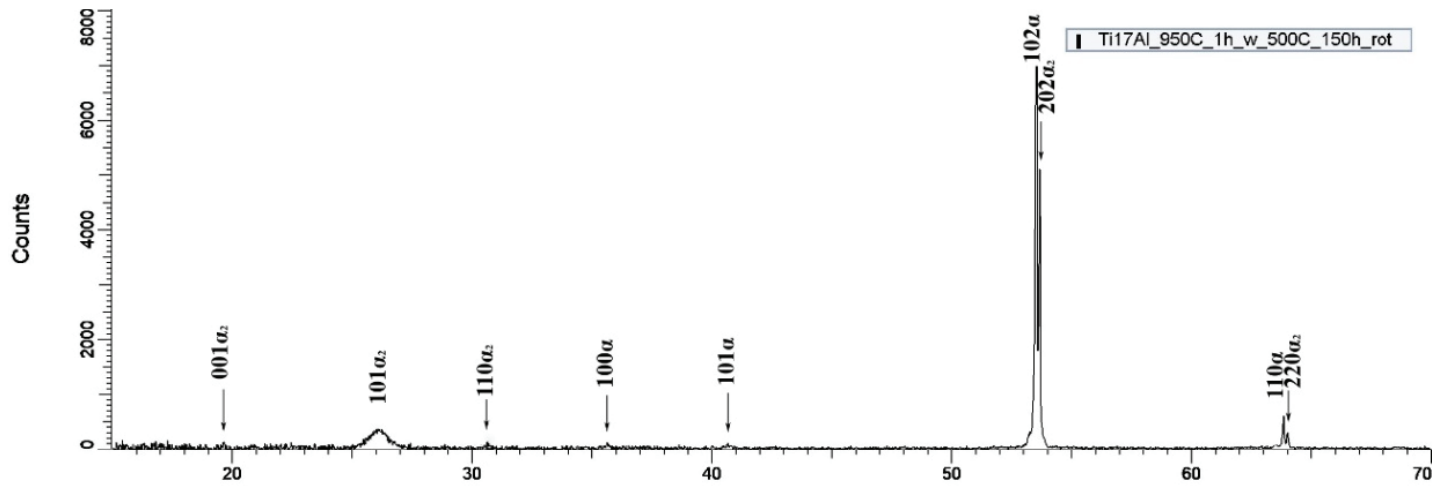

$\mathrm{b}$

Figure 1: Diffraction patterns of the samples after heating to $950^{\circ} \mathrm{C}$ with an exposure of 1 hour and subsequent aging at $500^{\circ} \mathrm{C}$ with an exposure: $\mathrm{a}-100$ hours; $\mathrm{b}-150$ hours.

Brighter reflections of the $\alpha_{2}$-phase were observed on microelectron diffraction patterns after aging. The aging of the alloy for 100 hours leads to an increase in the number of dispersed particles of the $\alpha_{2}$ phase (Fig. 2, a), but does not lead to a significant change in their size relative to the treatments carried out in previous work [7]. Subsequent heat treatment with quenching from $950{ }^{\circ} \mathrm{C}$ and aging at $500{ }^{\circ} \mathrm{C}$ with a duration of 150 hours 
does not lead to a significant growth of $\alpha_{2}$-phase particles (Fig. 2, b). The average particle size after this treatment reaches $10-20 \mathrm{~nm}$.

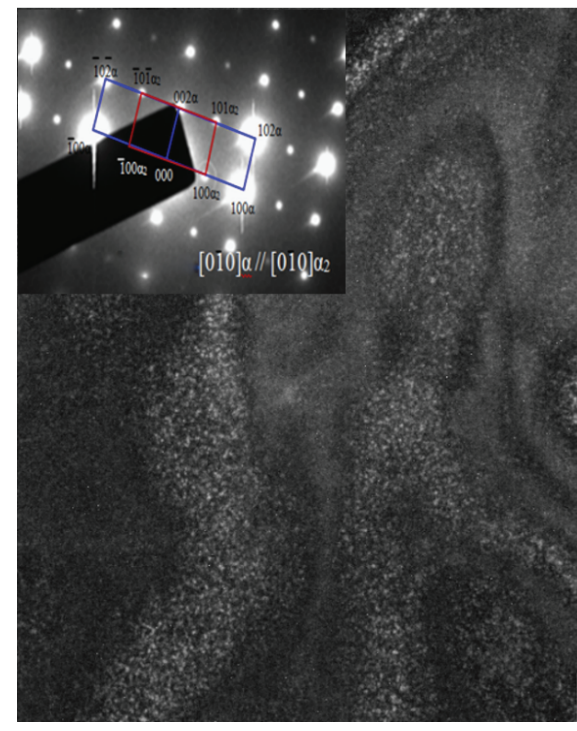

a

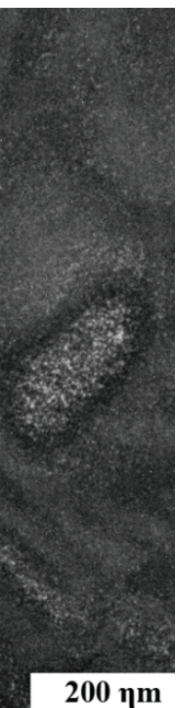

$200 \eta \mathbf{m}$

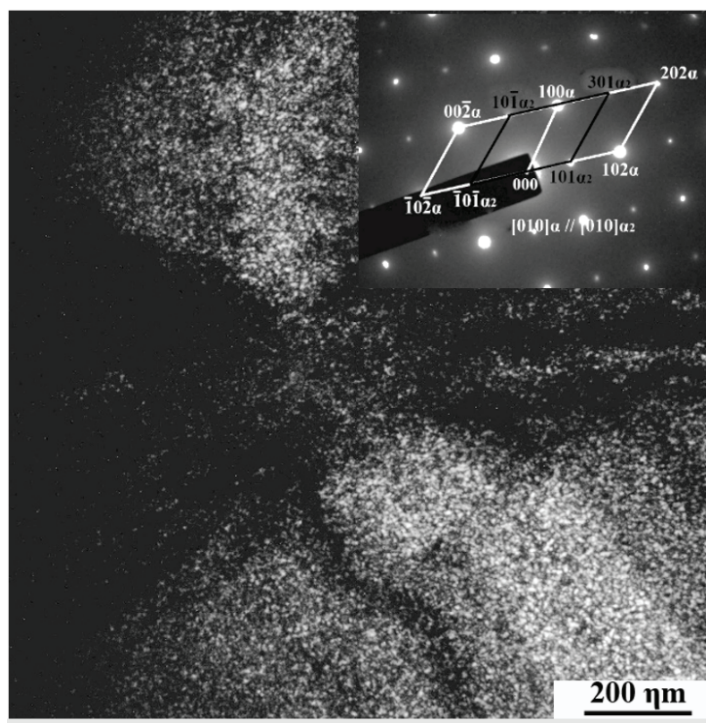

b

Figure 2: The microstructure of the alloy Ti17Al after high-temperature treatment at $950^{\circ} \mathrm{C}$ with an exposure of 1 hour and aging at $500^{\circ} \mathrm{C}$ with an exposure: $\mathrm{a}-100$ hours; $b-150$ hours.

It was decided to increase the aging temperature of the alloy to $650^{\circ} \mathrm{C}$ and the exposure time to 150 and 300 hours at the next stage of the study. According to the results of X-ray structural phase analysis, it can be seen that the volume fraction of the $\alpha_{2}$-phase increases with increasing exposure time at a given temperature (Fig. 3 ).

An electron microscopic study showed that the electron diffraction patterns showed clear, bright reflections of the ordered Ti3Al phase on the samples after aging for 300 hours. However, particles of the ordered $\alpha_{2}$ phase were still observed in the obtained dark-field images. The sizes of these particles have increased in comparison with the previous treatments and are approximately equal 40-50 nm (Fig.4, a).

From this it follows that carrying out treatments with both supercooling and aging after quenching for the Ti17Al alloy leads to the formation of only dispersed particles of the $\alpha_{2}$ phase in the structure, which means the transformation under the mechanism of nucleation and growth, and, consequently, the formation of a two-phase structure by heterogeneous transformation. However, carrying out several similar heat treatments of a single-phase Ti26Al alloy leads to the formation of antiphase boundaries of the thermal type, and, consequently, the passage of the transformation by a homogeneous mechanism. 


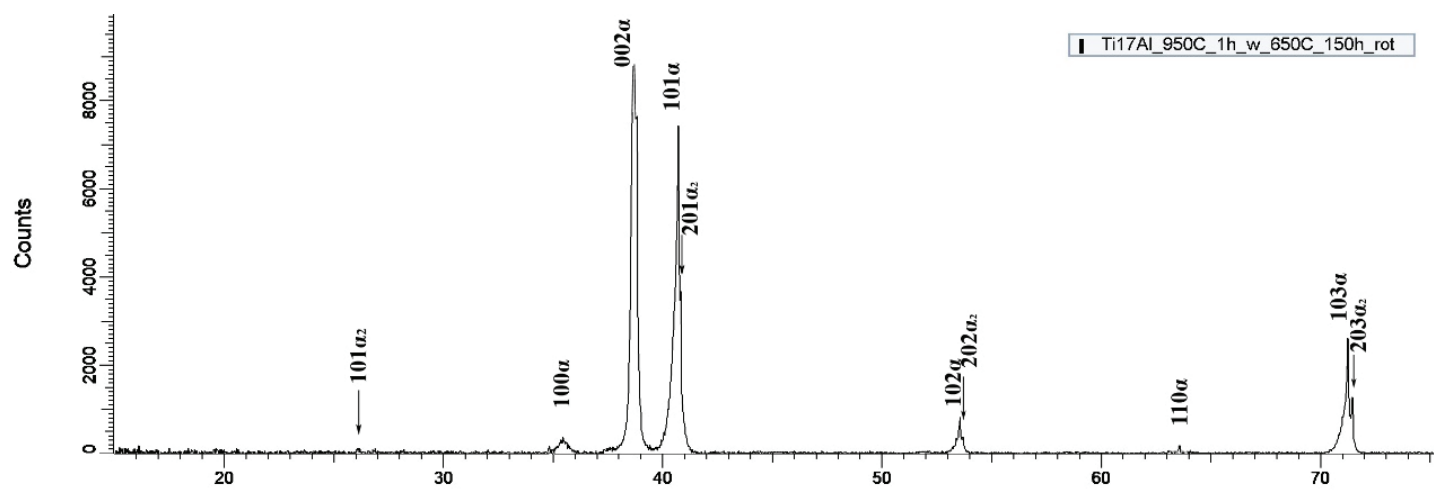

$\mathrm{a}$

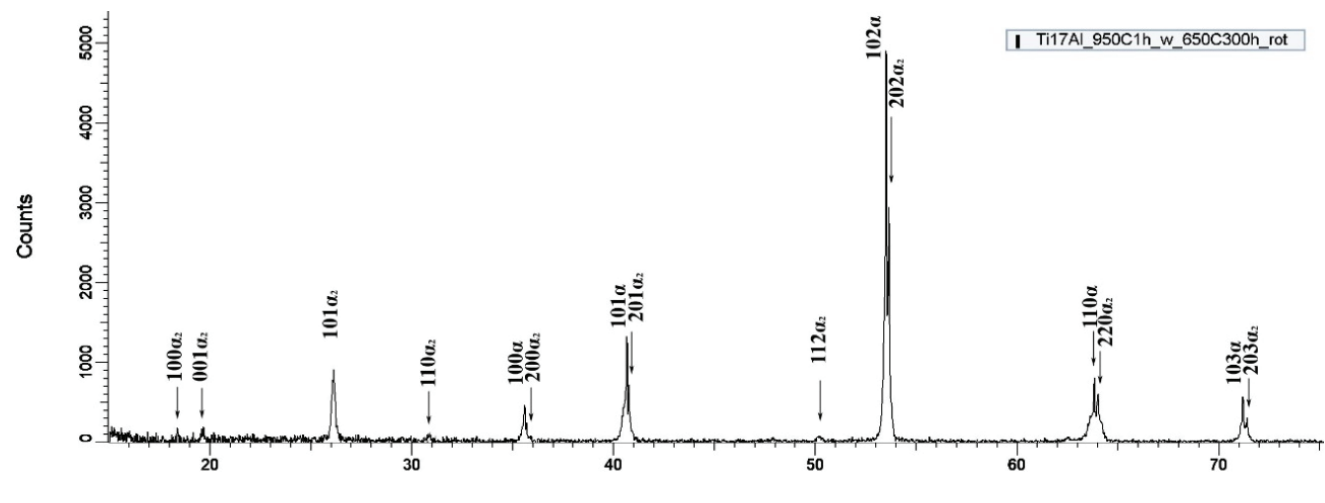

b

Figure 3: Diffraction patterns of the samples after heating to $950^{\circ} \mathrm{C}$ with a holding time of 1 hour and subsequent aging at $650^{\circ} \mathrm{C}$ with a holding time: $\mathrm{a}-150$ hours; $\mathrm{b}-300$ hours.
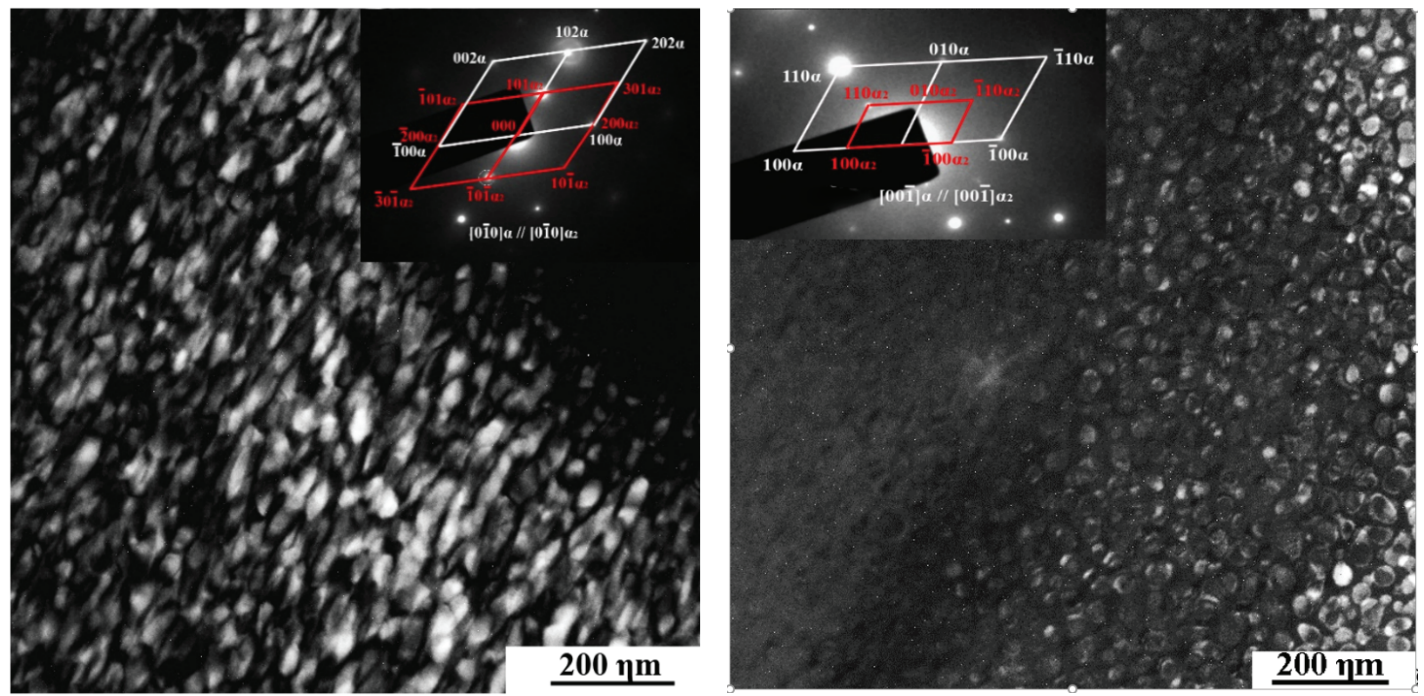

Figure 4: The microstructure of the alloy Ti17Al after high temperature treatment at $950^{\circ} \mathrm{C}$ with an exposure of 1 hour and aging at $650^{\circ} \mathrm{C}$ with an exposure of 300 hours. 


\section{Conclusions}

It was established that in the Ti-17 at.\% Al alloy, the formation of particles of the ordered $\alpha_{2}$ phase in the process of aging after quenching or processing with supercooling in the temperature range of $400 \ldots 650^{\circ} \mathrm{C}$ occurs as a phase transformation of nucleation and growth. The size of the forming particles increases with increasing exposure time and temperature. Signs of homogeneous $\alpha \rightarrow \alpha_{2}$ transformation not detected.

\section{Acknowledgements}

The study was supported by the grant of the Russian Science Foundation № 18-1300220

The work was carried out using the laboratory equipment "Structural methods of analysis and properties of materials and nanomaterials" of the Center of Ural Federal University.

\section{References}

[1] D.J. Evans, T.F. Broderick, J.B. Woodhouse, et al., The role of intermetallic precipitates in Ti-62222S, Materials Science and Engineering: A V. 213 (1-2) (1996) 37 - 44.

[2] D. Lunt, T. Busolo, X. Xu, et al., Effect of nanoscale $\alpha_{2}$ precipitation on strain localisation in a two-phase Ti-alloy, Acta Mat. 129 (2017) $72-82$.

[3] A.A. Popov, M.A. Popova, N.G. Rossina, The effect of alloying on the ordering processes in near-alpha titanium alloys, Materials Science and Engineering: A. 564 (2013) $284-287$.

[4] S. Sircar, K. Narasimhan, K. Mukherjee, An investigation of the ordered D019 phase formation in the Ti-Al system, J. Mat. Sci. 21 (1986) 41434146.

[5] M. J. Blackburn, The ordering transformation in titanium: aluminium alloys containing up to 25 at. Pct aluminium, Transactions of the metallurgical society of AIME 239 (1967) $1200-1208$.

[6] M.A. Popova, N.G. Rossina, K.I. Petrova, Precipitation of $\alpha_{2}$-Phase in TitaniumAluminum Alloys, Metal Science and Heat Treatment 57 (7-8) (2015) 469 - 472.

[7] A.A. Popov, K.I. Lugovaya, N.G. Rossina, M.A. Zhilyakova, Investigation of the Mechanism of Precipitation of the $\alpha 2$-phase in a Two-Phase Titanium - Aluminum Alloy, Metal Science and Heat Treatment 60 (5-6) (2018) 303 - 307. 
[8] T.N. Kochetkova, A.B. Notkin, Ye.I. Teytel', Yu.I. Potapenko, M.G. Gaydukov, I.V. Levin, Influence of the structural state on creep resistance of alloy Ti-5Al, Physics of Metals and Metallography 69 (4) (1990) 176-182.

[9] H. Wood, G.D.W. Smith, A. Cerezo, Short range order and phase separation in Ti-Al alloys, Materials Science and Engineering: A 250 (1) 83-87. 